\title{
University Rankings and Governance by Metrics and Algorithms
}

George Chen ${ }^{1}$, Leslie Chan ${ }^{2}$

1. JD Student at Harvard Law School

2. University of Toronto Scarborough

This is a draft chapter. The final version will be available in the Research Handbook on University Rankings: Theory, Methodology, Influence and Impact, edited by Ellen Hazelkorn and Georgiana Mihut, forthcoming 2021, Edward Elgar Publishing Ltd.

\section{Introduction}

Around the world, university rankings have become evaluation and decision-making tools utilized by a multitude of stakeholders beyond the university (Hazelkorn, 2008, 2016). The numbers and types of university rankings and methodologies have proliferated in recent years, but bibliometric performance as measured in total publication output and citation impact continue to play a significant role in determining institutional rankings (Robinson-Garcia et. al. 2019).

Not surprisingly, there has been much debates on the nature and adequacy of various bibliometric and non-bibliometric indicators for determining rankings (Taylor \& Braddock, 2007; Zitt \& Filliatreau, 2007; Adler \& Harzing, 2009; Safon, 2013; Bougnol \& Dula, 2014; Soh, 2014; Hazelkorn, 2016; Dogan \& Al, 2019). However, there are less emphasis on the relationship between the firms that produce rankings and the publishers/data analytics firms supplying bibliometric data for rankings and the potential conflict this may create. Understanding the behaviour of data analytics firms around rankings is therefore crucial. This is particularly important because publishers/data analytics firms such as Elsevier have been acquiring and consolidating research infrastructure to create platforms for the entire research workflow, including publishing and subsequent research evaluation. Their platform simultaneously extracts data from the broad range of research activities to develop products and services that lock-in institutional users with the promise of higher rankings (Posada \& Chen, 2018; Andrews 2018; Aspesi \& Brand 2020). So while generating dependencies from universities through the citation 
metrics and analytic products they develop, the same firms supply bibliometric data to companies developing rankings that incentivise researchers to publish in the journals they own. Given these dual roles, it is important to analyze publisher/data analytics firms' behaviour surrounding the promotion and support of rankings and the potential conflict of interests.

This paper looks closely at how data analytic providers leverage rankings as a part of their strategies to further extract rent and assets from the university beyond their traditional roles as publishers and citation data providers. Multinational publishers such as Elsevier, with over 2,500 journals in its portfolio, has transitioned to become a data analytic firm. Rankings expand their abilities to monetize further their existing journal holdings, as there is a strong association between publication in high-impact journals and improvement in rankings. The global academic publishing industry has become highly oligopolistic, and a small handful of legacy multinational firms are now publishing the majority of the world's research output (See Larivière et. al. 2015; Fyfe et. al. 2017; Posada \& Chen, 2018). It is therefore crucial that their roles and enormous market power in influencing university rankings be more closely scrutinized.

We suggest that due to a combination of a lack of transparency regarding, for example, Elsevier's data services and products and their self-positioning as a key intermediary in the commercial rankings business, they have managed to evade the social responsibilities and scrutiny that come with occupying such a critical public function in university evaluation. As the quest for ever-higher rankings often works in conflict with universities' public missions, it is critical to raise questions about the governance of such private digital platforms and the compatibility between their private interests and the maintenance of universities' public values. These values include knowledge as public goods, academic freedom, diversity and social inclusion, racial equity, trust, transparency, accountability, autonomy, democratic control, and good governance, to name just a few (Fitzpatrick 2019). Analytics providers often promote their tools and infrastructure to university administrators as value-neutral and their services and products as data-driven and objective, designed to provide greater efficiency and competitive advantage. Yet researchers and faculty are seldom involved in the decision-making about the procurement and adoption of these often large-scale infrastructures. However, researchers and faculty are required to use them once these contracts are made (Lim 2019). The question of what social values institutions of higher education are giving up by buying into tools which use metrics derived from corporate logic is seldom asked (Styhre 2018; van Djick et al. 2018). 
In this paper, we examine the entangled relationship of publisher/data analytic firms and ranking companies. Using Elsevier as a case study, we map the development of their end-to-end publishing, data analytic and research intelligence platform with their visible role as a service provider and their invisible role in public governance using their infrastructure power (Easterling 2016; Williamson 2018). We draw on the framework of Platform Capitalism and Platform Society (Srnicek 2016; van Dijck, Poell, \& Waal, 2018; Zuboff 2019) to help explain the strategies of platformization and rentiership by Elsevier (Posada and Chen 2018). van Dijck et. al (2018 and van Dijck 2013, 2014) define platforms as programmable digital architectures bringing into interaction users, corporate entities, and public institutions. Platforms are the new intermediaries between users, i.e. providers of goods and services, advertisers and consumers. Being digital and networked, platforms are well equipped to amass, manage and create new assets out of big data using machine learning and algorithms. The goal is to generate predictions of user's behaviour and actually influence user's behaviour as determined by the designer of the platform (Yeung, 2017; Zuboff 2019).

According to van Djick et al (2018), the development strategy of a platform generally relies on three processes: i) datafication, the process of systematically and incessantly capturing users activities and interactions and turning them into discrete, quantifiable data; ii) commodification, meaning transforming the extracted data into tradable commodity or assets once they have been collected and curated; and iii) selection of users' data and activity for the development of new predictive products and assets for further profit extraction. Platforms are thus more than simply intermediaries that provide a place for different entities to interact. They are infrastructures that enable the development of applications or web services that guide or structure user interactions and relations through an invisible form of Algorithmic Governance. (Danaher et. al., 2017). This refers to "a form of social ordering that relies on coordination between actors, [which] is based on rules and incorporates particularly complex computerbased epistemic procedures," but are not transparent to those whose behaviour are being shaped (Katzenbach \& Ulbricht 2019).

We are most familiar with infrastructural platforms of the "big five" (Google, Amazon, Facebook, Apple, and Microsoft), sectoral platforms such as Uber and Airbnb, and MOOCs in higher education. But we know relatively little about the new forms of academic platforms such as those being built by Elsevier and its parent company RELX. The new platforms are designed as end-to-end systems to capture the entire academic knowledge production cycle from conception to publication and distribution and subsequent evaluation and reputation management. While 
generating new data to feed into a growing array of rankings, the system in turn reinforces users participation in the process (Posada and Chen 2018; Chen et. al. 2019; Lim 2019). Such platforms are underpinned by algorithms or decision-making tools that are powerful new ways to guide, shape and influence researcher's behaviour and university governance. However, these new tools are mostly opaque and are not subjected to public audit or scrutiny, therefore potentially containing unexamined biases both in the data and in the algorithms with unknown implications (Pasquale 2015).

There is now a growing scholarship across the disciplines - from information science, media studies, sociology, criminology, legal studies and management studies - examining the societal and ethical implications of algorithmic surveillance and the social justice implications across sectors (O’Neil 2017; Noble 2018; Ferguson 2017; Eubanks 2018; Young et. al. 2019; Kellogg et al. 2019; Ashri 2020). However, scholars have paid relatively little attention to how algorithms and data automation have been reshaping the governance decision-making process of higher education by way of rankings (Williamson 2018). This paper documents these emerging developments and explores their potential impact on the university's public missions and values while pointing to areas for further research.

\section{Methodologies and Data Sources}

To understand data analytics firms' involvement with rankings, it is important first to recognize the high profitability of both the data analytics and the rankings industries. In addition to Elsevier, we provide indirect evidence of the profitability of the industries by looking at Clarivate Analytics and Times Higher Education World University Rankings, which has seen a prominent rise in recent years in the global ranking industry. Clarivate Analytics, a private equity firm ${ }^{1}$, is the current owner of the well-known and widely used Web of Science bibliometric database, Science Citation Index and the Journal Impact Factor, formerly owned by Thomson Reuters.

With regard to the relationships between data analytics and rankings firms, we also contrast the distinct strategies of Elsevier and Clarivate Analytics. While Elsevier's growing involvement with rankings since 2007 reflects its broader strategies of extracting values and rents from universities through publishing and research infrastructure and data analytics products,

\footnotetext{
${ }^{1}$ Private Equity firms traditionally buy public companies with debt and make them private. Changes such as cost cutting measures, strategic changes and financial restructuring are made for the acquired company to increase profitability. The company is then sold for a profit by the private equity firm.
} 
Clarivate leverages their dominance in database ownership to become a volume leader in international rankings support, providing data to multiple ranking firms.

To understand the profitability of the rankings and data industries, we conducted a literature search of the financial news sources and reviewed the firms' annual reports where available. To examine the involvement of rankings by publishers/data analytics firms, we examined a combination of external news sources, rankers' press releases, and information provided by the firms, including promotional materials. Such sources include over 4400 press releases as well as over 100 pieces of promotional material from Elsevier's "Resource library" available online ${ }^{2}$. We also reviewed over 175 press releases from Clarivate as well as the articles from Clarivate libguide available online ${ }^{3}$.

The collected information was limited to materials publicly available or publicly promoted by the firms, and thus frequently reflects what the rankers and data analytics firms intend to promote, rather than empirical studies of the ranking instruments. The firms under review have not published such empirical studies but instead rely primarily on in-house reports and marketing materials to generate awareness of their products. However the power of such promotional materials and how they are further consumed by university leaders through the media that promotes rankings should not be underestimated. Indeed Times Higher Education began as a magazine and continues to act as a media company that supplies higher education news articles and promotes its rankings through popular media (Stack, 2016). The marketing materials are also telling because as Beer (2018) noted, analytic firms use these materials to construct a set of "data analytic imaginaries" with great promises of return on investment and competitive advantages. These imaginaries further incentivize further "datafication" as mentioned earlier. Thus a critical analysis of the available marketing information provides important clues about the data analytics - ranker relationship.

\section{Clarivate Analytics (Web of Science)}

Clarivate Analytics' Web of Science citations database was initially launched in 1964, in print format, as the Science Citation Index ( $\mathrm{SCI}$ ) by the Institute for Scientific Information, or ISI (Garfield, 2009). SCI was unprofitable for ISI until the 1970s, only becoming profitable with the

\footnotetext{
${ }^{2}$ https://www.elsevier.com/research-intelligence/resource-library

${ }^{3}$ https://clarivate.libguides.com/home
} 
rise of citation analysis in funding decisions (Wouters, 2017). ISI continued selling a myriad of bibliometrics-related products until 1988, when it was bought out by JPT Publishing for 24 million USD (Highbeam Research, 1992). ISI was a highly attractive subsidiary, however, as Elsevier was rumoured to have aggressively negotiated for the purchase of the subsidiary from JPT in 1992 (Lane, 1992). Thomson Reuters, the world's largest international multimedia news and financial information provider, ultimately purchased the entire JPT Publishing company, for which ISI was the largest subsidiary, for 210 million USD (Highbeam Research, 1992). The sale of JPT for ten times ISI's initial purchase price reflects the growing profitability of the citation analysis field.

Thomson Reuters continued to sell citation data in the form of the Web of Science, the core of which was ISI's SCI. This was complemented by the development of a myriad of analytics products including inCites in 2009 (Information Today, 2009). The entirety of Thomson Reuter's intellectual property (IP) and science arm was acquired in 2016 by Onex, a Canadian investment firm, and Baring Asia, a private equity firm for 3.55 billion USD (Onex, 2016). This spun-off business then became Clarivate Analytics. It is important to note that the 3.55 billion USD covered the entire IP and science arm, not merely citations-related products. In 2019, Churchill Capital, a public investment vehicle, merged with Clarivate, with the merger valuing Clarivate at 4.2 billion USD (Clarivate, 2019a). The price tag of 24 million USD purchase of ISI by JPT, to the consolidation of a data analytics firm with an investment firm for 4.2 billion USD in three decades reflects the data provider/analytics industry's profitability and the importance of universities as the site of profit extraction (Paasi 2015; Aspesi et. al. 2019).

\section{Times Higher Education World University Rankings}

The Times Higher Education ranking was introduced in 2004 as a collaboration between Quacquarelli Symonds (QS) and Times Higher Education ${ }^{4}$ (Labi, 2010). This initial ranking utilized the QS rankings' current methodology while being published in the Times Higher Education newsmagazine (Labi, 2010). Times Higher Education itself was initially owned by News International through TSL Education (Budden \& Chassany, 2013). TSL Education was sold in 2005 to Exponent Private Equity for 235 million GBP (Budden \& Chassany, 2013). Here, it is unclear whether rankings were the primary driver of this sale, as the current iteration of the THE rankings was a collaboration between two firms. The profitability of TSL Education led to a

\footnotetext{
${ }^{4}$ To distinguish the THE magazine from the THE rankings, we italicized the former.
} 
further sale to Charterhouse Capital Partners in 2007 (Budden \& Chassany, 2013). TPG then acquired TSL Education at an estimated value of 400 million pounds in 2013 (Budden \& Chassany, 2013). While the amount has shown a clear increase from the 2005 sale price, it is again unclear whether rankings were a driver of the increased value. After all, Times Higher Education had only started its own rankings for two years at this point.

It was the 2018 sale of TSL Education (since rebranded to TES Global (2014)) by TPG that truly demonstrated the value of the rankings business. Notably, the THE World University Rankings was explicitly excluded from the sale of TES Global to Providence Equity Partners in 2018 (TES Global, 2018). Amongst other companies, Elsevier attempted to purchase the THE World University Rankings at the time (Alliance News, 2018). Ultimately, Times Higher Education was acquired by Inflexion, another private equity firm, with the firm emphasizing its intent to grow Times Higher Education Rankings into the US and Asia, where many established and emerging universities have bought into the global ranking agenda (Inflexion, 2019).

The sale of Times Higher Education Rankings emphasizes the profit appeal of rankings, as both Elsevier and Inflexion attempted to acquire the business. Inflexion's subsequent emphasis on expanding the Times Higher Education Ranking's reach into the US and Asia, places where existing rankings such as US News and World Report and QS dominate, suggests the presence of lucrative markets where strong demand exists for rankings products. The Mitsui Group's purchase of $25 \%$ stake in QS as a part of QS' Asian expansion further reflects the lucrativeness of the rankings business (Mitsui Group, 2015). Ultimately, just as private equity became involved in Clarivate due to the data analytics business's lucrative nature, so too has private equity involved itself into the highly profitable rankings business.

\section{The Role of Bibliometrics and Expertise Enhancing Processes in Rankings}

With the proliferation of international university rankings, scholarship (Aguillo, Bar-llan, Levene, Ortega, 2010; Hazelkorn, 2016; Vernon, Balas, \& Momani, 2018) has attempted to classify rankings by target audience (i.e. research, students) as well as by indicators (i.e. reputation, learning environment). We introduce here a simplified two-dimensional rankings typology to contextualise the relationship between rankers and different data providers as well as to contrast the approaches of Clarivate and Elsevier:

- Bibliometric predominance: refers to the degree to which a ranking is weighted towards bibliometric indicators versus other indicators such as student counts and full 
time faculty. Here, bibliometrics-oriented rankings are rankings for which institution performance is substantially based on bibliometrics. The U.S. News and World Report International Rankings for which bibliometrics indicators represent $75 \%$ of the overall score (Morse \& Vega-Rodriguez, 2019) is one such example. In contrast, multicategorical rankings have institutional performance driven by a multitude of factors other than bibliometrics. QS is an example of a multi-categorical ranking, as reputation represents $50 \%$ of the overall score (QS, 2020). ${ }^{5}$

- Expertise Enhancement: To the extent that stakeholders adopt a ranking as legitimate, a ranker has gained power in its ability to choose and weight indicators, thereby determining its "importance". The choice of indicators further grants the ranker a form of "expertise" or authority, as the rules underlying the indicators are not always transparent to the outsider ( $\operatorname{Lim} 2017$ ). This is not the case for all indicators: after all, ARWU's Award indicator, which merely counts the number of awards won by an institution's staff (ARWU, 2020) does not grant ARWU material "expertise." The process is easily understood and easily replicable if needed. Instead, "expertise" is often obtained through the use of data generated specifically for a given ranking or through reducing indicator transparency (with the information asymmetry increasing ranker "expertise"). Nonreplicability may also be a factor that contributes to the building of "expertise". THE and QS' in-house reputation surveys are examples of specifically generated data; and in this sense, all normalised ${ }^{6}$ bibliometric indicators generate some form of "expertise". But some bibliometric indicators such as those for THE can generate greater amounts of "expertise" by not revealing their normalisation algorithm or providing transparent explanations of their process.

The rankers' more advantageous position with respect to "expertise enhancing" indicators is especially salient with multi-categorical rankings where performance is not only measured in bibliometric terms. While "expertise" is generated from a ranker's in-house transformations in addition to bibliometric indicators, they are nevertheless based on bibliometric data external to the ranker. On the other hand, non-bibliometric indicators have the potential to be highly

\footnotetext{
${ }^{5}$ This is without commenting on the potential correlations of various indicators to bibliometrics (see e.g. Soh, 2015; Robinson-Garcia et al., 2019).

${ }^{6}$ Normalisation refers to the adjustment of raw values by some factor or algorithm. Citations data is frequently "normalised" as an attempt to reflect differences in publication patterns between fields.
} 
"expertise enhancing" as in the case of reputation, where the ranker determines the collection and calculation process.

The differing approaches taken by Elsevier and Clarivate to rankings can be clearly shown when applying the categorizations above to an illustrative list of international rankings drawn from existing scholarly literature (Hazelkorn, 2016; Vernon et al., 2018) and a conference presentation by an international rankings consultant (Guhr, 2019).

Table 1: A Two Dimensional Typology of Rankings

\begin{tabular}{|c|c|c|}
\hline & Less Expertise Enhancement & $\begin{array}{l}\text { Substantially Expertise } \\
\text { Enhancing }\end{array}$ \\
\hline Non-bibliometric & 4ICU/UniRank & $\begin{array}{l}\text { Global University } \\
\text { Employability Ranking } \\
\text { (GEURS) (Emerging) } \\
\text { UI GreenMetric } \\
\text { RankPro Worldwide } \\
\text { Professional University } \\
\text { Rankings } \\
\text { Youth Inc Global University } \\
\text { Rankings }\end{array}$ \\
\hline Multi-categorical & $\begin{array}{l}\text { Center for World University } \\
\text { Rankings (CWUR) } \\
\text { Three University Missions } \\
\text { Moscow International } \\
\text { University Ranking (MosIUR) } \\
\text { Most Innovative Universities } \\
\text { Rankings (MIUR) } \\
\text { Round University Ranking } \\
\text { (RUR) } \\
\text { Webometrics }\end{array}$ & $\begin{array}{l}\text { QS } \\
\text { THE } \\
\text { U-Multirank }\end{array}$ \\
\hline Bibliometrics oriented & $\begin{array}{l}\text { A3 - Academic Ranking for } \\
\text { Academics by Academics } \\
\text { ARWU } \\
\text { CWTS } \\
\text { Nature Index } \\
\text { National Taiwan University } \\
\text { Ranking (NTU) } \\
\text { SCImago } \\
\text { University Ranking by } \\
\text { Academic Performance } \\
\text { (URAP) } \\
\text { USNWR }\end{array}$ & $\begin{array}{l}\text { The } 100 \text { Best Universities in } \\
\text { the World Today (The Best } \\
\text { Schools) } \\
\text { In4M Metric Global Institution } \\
\text { Rankings (Lens.org) }\end{array}$ \\
\hline
\end{tabular}


Note: Both dimensions are continuums and the above break down into categories serve as a simplification designed to illustrate the contrasting approaches of Clarivate and Elsevier.

While the most common variety of rankings are bibliometrics-oriented rankings (10 out of the 23 rankings classified in Table 1 above), the most successful commercial rankings for their owners, QS and THE, are both Multi-Categorical as well as "Substantially Expertise Enhancing". The latter in effect encourages universities to engage with the rankers due to the rankers' active packaging and control of their data and processes. The deliberate involvement of Elsevier with such successful commercial rankers strongly contrasts with Clarivate's strategy of being the dominant provider of bibliometrics data to rankers (see table 2).

\section{Clarivate - Volume Domination in Rankings}

Table 2: Rankings - Clarivate supplied data (bold)

\begin{tabular}{|l|l|l|}
\hline & Less Expertise Enhancement & $\begin{array}{l}\text { Substantially Expertise } \\
\text { Enhancing }\end{array}$ \\
\hline Non-bibliometric & 4ICU/UniRank & $\begin{array}{l}\text { GEURS (Emerging) } \\
\text { UI GreenMetric } \\
\text { RankPro } \\
\text { Youth Inc }\end{array}$ \\
\hline Multi-Categorical & $\begin{array}{l}\text { QS } \\
\text { THE } \\
\text { CWUR } \\
\text { MosIUR } \\
\text { MIUR } \\
\text { RUR } \\
\text { Webometrics }\end{array}$ & U-Multirank \\
\hline Bibliometrics oriented & A3 & The Best Schools \\
& ARWU & Lens.org \\
& CWTS & \\
& Nature Index & \\
& NTU & \\
& SClmago & \\
& URAP & \\
& USNWR & \\
\hline
\end{tabular}

Rankings that use Clarivate's data include key international players such as ARWU, USNWR, and NTU (Guhr, 2019), in addition to the CWTS ranking which powers the bibliometrics of Umultirank. While Clarivate produces the ubiquitous Web of Science, rankings such as RUR and USNWR utilize additional Clarivate products such as $\operatorname{InCites}^{7}$ and Clarivate's Global Institutional

\footnotetext{
${ }^{7}$ InCites is a citations-based research benchmarking / analytics tool similar to SciVal.
} 
Profiles Project (GIPP) ${ }^{8}$ (RUR, 2019; Morse \& Vega-Rodriguez, 2019). Clarivate's products are prevalent in the rankings mentioned above.

\section{Elsevier - Product / Rankings Integration}

Unlike Clarivate's volume domination in providing data for international rankings, Elsevier supplies the data for four global rankings listed above (five including data supplied to the Three University Missions Moscow International University Rankings that describe themselves as being a partner with Clarivate). Elsevier has emphasized its support of regionally and internationally dominant rankings, particularly those that are both Multi-Categorical as well as Substantially Expertise Enhancing. It is important to note that Clarivate has branded itself as the neutral data analytics supplier to researchers and librarians, contrasting itself with Elsevier, which is both the publishers, analytics maker, and the exclusive bibliometric data providers to THE.

\section{Support of Multi-Categorical Commercial Rankings}

Elsevier has been heavily involved in both QS and THE, both rankings that had initially partnered with Thomson Reuters (now Clarivate). The switch of the two rankers to Elsevier may have been the result of an explicit rankings orientation by Elsevier. QS, then QS-THE, had earlier moved from Web of Science to Scopus in 2007 (Elsevier, 2007), three years after the launch of Scopus by Elsevier (Elsevier, 2004). While the QS Head of Research suggested the move to Elsevier was due to Scopus's comprehensive indexing (Sowter, 2007), Elsevier had been explicitly courting rankings around this time. For example, Elsevier sponsored the rankersoriented International Rankings Expert Group conference in 2007, presenting Scopus at a special session (IREG, 2007). In fact, QS was one of the first rankings to move to Scopus, as other rankings contemporary to QS-THE (i.e.: NTU, ARWU, Leiden) were utilizing Web of Science until the launch of the Scimago Institutions Rankings in 2009 (Scimago, 2009). This arrangement continued with THE. While THE had initially swapped back to Thomson Reuters in their breakaway from QS in 2009 (Mroz, 2009), by 2014 Elsevier was once again THE's partner (Jobbins, 2014). The figure below (original) chronicles the growing involvement of Elsevier in rankings through its relationship with THE.

\footnotetext{
${ }^{8}$ The Global Institutional Profiles Project combines reputational surveys and faculty / student demographics data to create a benchmarking dataset of institutions.
} 
Figure 1: Timeline of Key Elsevier Rankings Involvement

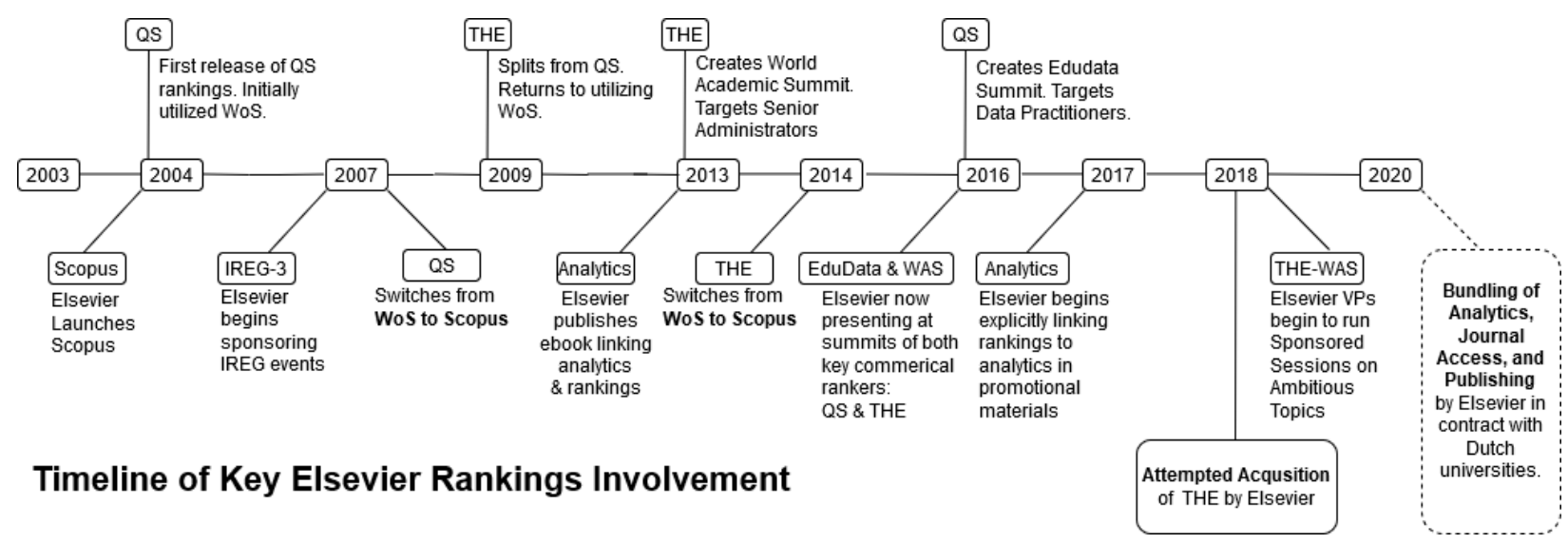

In 2013, Elsevier published Improving Your Research Management by Alan M. Johnson of the University of Technology Sydney. Targeting senior research managers, the free e-book emphasized the importance of succeeding in rankings as well as the utilization of data analytics products provided by Elsevier. While the impact on its target audience is unknown, Elsevier's choice to publish it could be seen as an attempt to expand the audience to the discourse and "data analytic imaginary" (Beer 2019) which they had previously promoted at IREG conferences.

Since the release of the 2013 ebook, Elsevier's reference to rankings in its promotional materials was one of subtle nudging, as improved rankings would be mentioned as a consequence of the adoption of new research strategy (facilitated by Elsevier products) by universities such as RMIT University (Elsevier, 2016). Promotional materials released did not explicitly emphasize the rankings connection until 2017 in the Elsevier Connect promotional articles and 2018 in the research intelligence pamphlets. A press release in 2017 by Covenant University explicitly showcased their improvement in THE ranking through the use of Scopus and SciVal (Nelissen, 2017). 2018 marked the release of promotional materials which echoed Elsevier's existing discourse at rankings conferences. Pamphlets such as "Data and Rankings: Show your university in its best light. 5 things to consider" (Elsevier, 2018) describe the importance of academic rankings and best practices in engaging with rankers. Elsevier described its capabilities in analyzing rankings as a part of various competencies for its Analytical Services (Elsevier, 2018). Elsevier also began utilizing rankings to promote its own metrics, showcasing the correlation of Elsevier's SciVal subject Prominence metric with the 
Field Weighted Citation Impact metric ${ }^{9}$ used as a basis for the THE citations indicator. This was described in Elsevier's 2019 promotional ebook “Understand Scopus and SciVal's role in university rankings" (Elsevier, 2019a). Elsevier's strategy to increase its involvement in rankings culminated with its attempt to acquire Times Higher Education in late 2018 (Alliance News, 2018). It would seem Elsevier planned to more tightly couple data analytics with the production of rankings, thereby mutually reinforcing their relationship and further their market power. While Elsevier do not own THE World University Rankings outright, they have formed a close alliance, including Elsevier's heavy use of promotional sessions at THE's conferences (ie: THE, 2018, THE, 2019a).

\section{Elsevier's Broader Valorization Strategy - Conflicts of interest and the Dutch Deal}

Chen, Posada, \& Chan (2019) documented Elsevier's strategy of horizontal (acquiring other journal titles) and vertical integration, creating an end-to-end platform that provides services from journal submission, data archiving, to peer review, journal publication, to subsequent dissemination, metric tracking and predictive analytics (see Fig. 2).

\footnotetext{
${ }^{9}$ Field Weighted Citation Impact is a normalised citations metric produced by Elsevier.
} 
Figure 2: Vertical Integration of Elsevier products

The Academic Knowledge Research Production Process

$\begin{array}{ccc}\text { The Research } & \text { The Publishing } & \text { The Evaluation } \\ \text { Process } & \text { Process } & \text { Process }\end{array}$

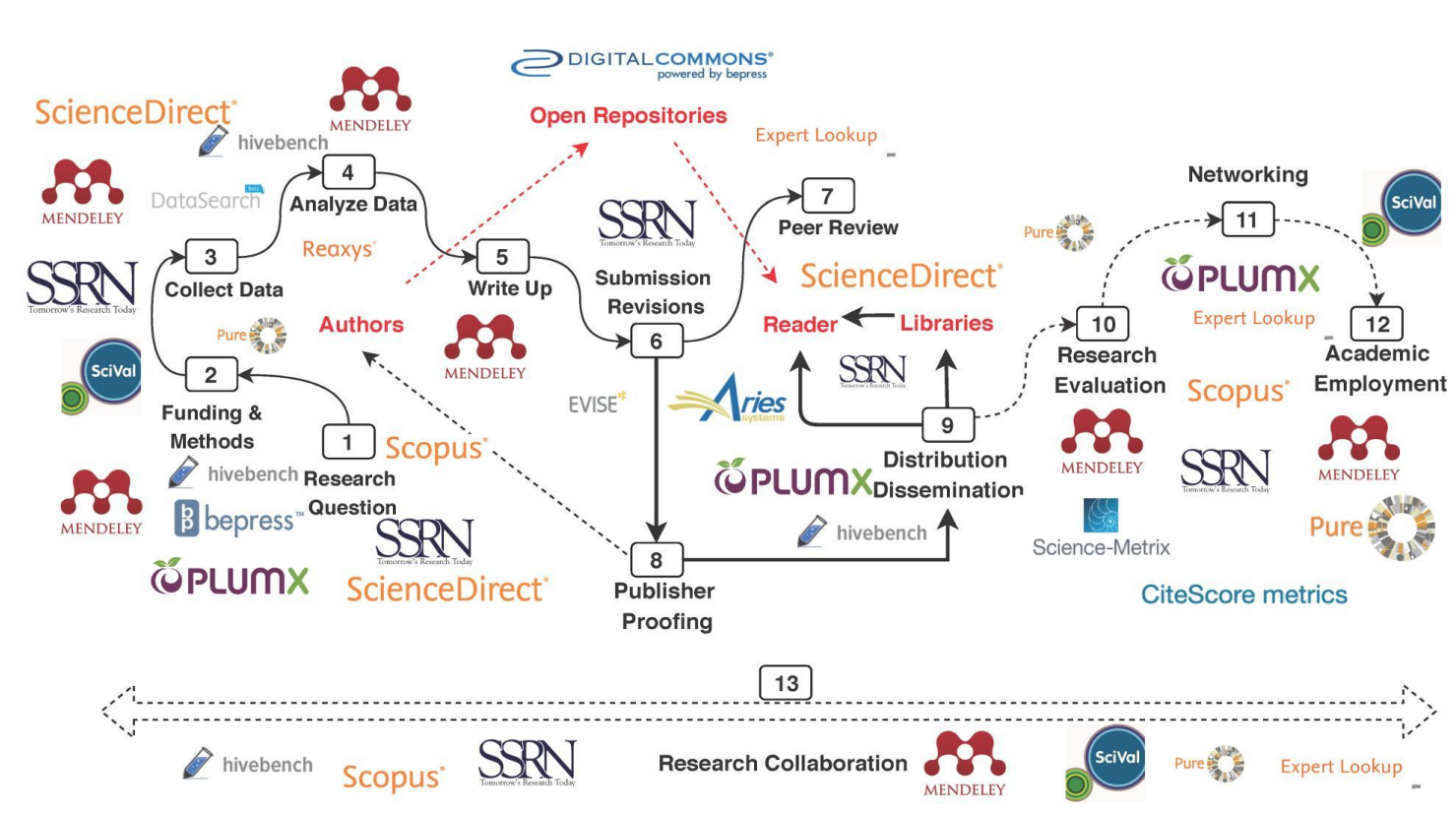

Source. Printed with permission. Chen, Posada, \& Chan, 2019.

By creating an end-to-end platform that integrates the entire research life cycle and reputation management, Elsevier is able to accumulate data that it can then leverage to create analytics products, particularly those supporting university competition on rankings. To further valorize these analytics, Elsevier has actively attempted to place itself into positions to influence the development and use of metrics by academic institutions and other organizations. For example, Elsevier's role as the sub-contractor for the European Commission's open science monitor and the corresponding use of Elsevier services such as Plum Analytics, Mendeley, and Scopus (Open Science Monitor, 2019) has been criticized for generating perverse incentives in researchers to use those very same products (Tennant, 2018).

In May 2020, Elsevier entered into an unprecedented deal with the Dutch universities (Association of Universities in the Netherlands (VSNU), the Netherlands Federation of University Medical Centres (NFU), and the Dutch Research Council (NWO)) (de Knecht, 2020). 
This $€ 16.4$ million per year deal offers Dutch university researchers gold open access publishing ${ }^{10}$ and journal access to Elsevier's journals in addition to Elsevier's professional services and collaboration in developing new research intelligence infrastructures (de Knecht, 2020). The significance of this deal is that Elsevier managed to gain access to researchers' data through the offering of new analytic products and services, essentially bundling together two previously separately procured university contracts into one. As academic publishing has increasingly moved towards the Open Access model, Elsevier's new contract accepts a form of Open Access while enabling the extraction of data from Dutch universities to enrich their analytics products aimed at Open Science. Through such a lock-in bundled contract, Elsevier has the potential to generate infrastructural dependencies as the contract describes the creation of a Pure Community Module to aggregate and duplicate data from existing Current Research Information Systems in the Netherlands (de Rijcke, 2020). A key concern, as expressed by de Rijcke (2020) is "that this deal may effectively transfer crucial means to influence Dutch science policy to a monopolistic private enterprise."

Among the many additional concerns is that the dependency on a commercial solution frequently leads to underinvestment in locally developed and internally-controlled infrastructure. The Dutch contract represents a complete buy-in into Elsevier's designed and controlled platform, as Open Access publishing occurs in Elsevier journals and the bibliometric data are managed, analyzed and curated by Elsevier's platform. In effect, we are seeing how enclosure and control over researchers' data could allow Elsevier to influence funders and university decision making through a new form of algorithmic governance and "undesired platform effects" (de Rijcke 2020, Aspeci and Brand 2020).

\section{Valorization of Analytics and Algorithmic Governance}

The use of bibliometrics as a "monitoring device" for university research management and policy development is not new (Moed et. Al., 1985; Garfield, 2009; Hazelkorn, 2016; Wouters, 2017). However, the vertical integration and bundling of the various Elsevier products into an end-toend platform is a relatively new development (Hinchliffe, 2018; Schonfeld). It signals a clear strategy on the part of Elsevier to focus on data analytics as a key revenue stream and to

\footnotetext{
${ }^{10}$ Without this deal, Dutch researchers would have to pay Elsevier an Article Processing Fee to publish in one of the journals. The fee could range from a couple of thousands to several thousand per article. (de Knecht 2020).
} 
monetize the "new oil" of researchers' personal information and digital "fingerprint", based on publication records and citation counts, research focuses, institutional affiliation, funding sources, and collaborative network. Combing data from these sources and adding machine learning to the mix allows Elsevier developers to create new forms of predictive "research intelligence" at scale and with great efficiency.

The sales pitch around these tools is that they allow institutions to create in-depth research profiles of their faculty, make visible research collaborations both statistically and graphically, promote more efficient searchers for knowledge and expertise, and above all, allow administrators to make decisions regarding resources allocation and even hiring decisions. "By aggregating and comparing Fingerprint indices of people, publications, funding opportunities and ideas, the Elsevier Fingerprint Engine reveals insightful connections with practical applications." (Elsevier, 2019c). Elsevier showcases how Arizona State University (ASU) identifying opioids research as a priority collaboration topic internally through the use of the Prominence indicator (Elsevier, 2020d).

The tools promise to bring algorithmic-based analytics to universities in an integrated package. Pure is promoted as being able to suggest collaboration partners (Elsevier, 2019b) while the algorithmically-generated grant recommendations of funding bodies can be directly imported into the Pure workflow (Elsevier, 2020c). According to the Pure website, the tool "facilitates an evidence-based execution of strategy to unlock your full research potential, leading to increased funding, improved international collaboration and greater visibility." 11

Elsevier sees universities in other parts of the world as ripe for their marketing. They have promoted its Fingerprint Engine, a text-mining algorithm that generates smart keywords, in their products Pure and Expert Lookup (Elsevier, 2019c), to National Cheng Kung University (NCKU) in Taiwan. Their promotional material shows how NCKU uses the algorithmically-generated keyword feature in Pure to search for international collaborators and to increase international visibility (Elsevier, 2020a). In another example, Elsevier showcases how Covenant University (Nigeria) uses Scopus and Scival to guide their research decisions and "in its 15 years, Covenant University has powered its way up the country's research rankings and is looking to compete internationally" (Nelissen 2017). In Egypt, Elsevier took part in the creation of a national rankings committee to assist universities in the country with visibility in world rankings. According to Elsevier, the use of their analytics has "enhanced the global reach of the country:

\footnotetext{
${ }^{11}$ https://www.elsevier.com/solutions/pure
} 
the percentage of international collaboration in Egypt rose above 50 percent for the first time in 2017. That meant more than half of the research output of Egyptian researchers had at least another co-author from another country demonstrating increased visibility with potential to attract funding, and strengthening relationships with other countries" (Duermeijer et al., 2018).

\section{Discussion}

The data-driven tools described above are marketed by firms to universities around the world as being "neutral" and unbiased, delivering to university administrators expert intelligence decisions and prediction of future success. These products would allow decision-makers to allocate resources according to the analytics, and further enhance their university's position in world rankings. One of the "undesired platform effects" is that universities adopting these analytics products may increasingly be susceptible to the algorithmically-generated indicators and search results provided by analytic firms. In this way, firms such as Elsevier create a form of invisible infrastructure dominance (Easterling 2016, Chan 2019) whereby they obtain increasing influence over university decision making while administrators are preoccupied with competitive efforts to gain higher rankings.

In effect what we are increasingly seeing is a form of panopticon system governed by opaque algorithms designed to extract data and value from academic institutions through incessant surveillance and monitoring (Zuboff 2019). Of course, only institutions with the financial resources can afford to contract these bundled publications and analytic tools to increase the visibility of their outputs, thus further reinforcing the hierarchy and inequality that rankings already produce (Amsler \& Bolsmann 2012, Stack 2016, Shattock 2017). At the same time, universities in the global South are given the promise that they can become visible in global university rankings if they buy into their platform. As Katzenbach \& Ulbricht noted (2019:11)

Algorithmic governance has many faces: it is seen as ordering, regulation and behaviour modification, as a form of management, of optimisation and of participation. Depending on the research area it is characterised by inscrutability, the inscription of values and interests, by efficiency and effectiveness, by power asymmetry, by social inclusiveness, new exclusions, competition, responsiveness, participation, co-creation and overload. For most observers, governance becomes more powerful, intrusive and pervasive with algorithmization and datafication. 
One of the effects of these technologies and platforms is that academics are under constant monitoring. Academics themselves are being conditioned to constantly check on their own profile and to improve their own metrics through publication (Pooley, 2018; Petre et. al. 2019; Lim 2019) and other forms of social media engagement, known as "altmetrics" (Thelwall et al. 2013; Repiso et al. 2019; Nuzzolese et al. 2019). However the underlying algorithms of the platforms are often non-transparent to the individual or the institutions which use them, and above all, the academics themselves are not in control of how their data are being gathered and reused. In essence, with products such as Pure and Expert Lookup, Elsevier effectively creates and curates the researcher's profile without the researcher's own input. After all, citation trends cannot be directly controlled by the researcher and the "Fingerprint Engine" is purely driven by text mining and pattern matching by the algorithms programmed by Elsevier's engineers.

More importantly, universities often do not have access to the algorithms in order to perform any audit. With institutions increasingly emphasizing quantifiable data to improve in the rankings and/or other such tools, the proclaimed accuracy and insightfulness of the platforms and the profiles they develop become increasingly a self-fulfilling prophecy. In this process, academics are increasingly compelled to behave in a manner that increases the value of the platforms and ultimately enriches the bottom-line of the corporations providing these platforms.

The algorithmic nature of the tools also impact decision-making at the institutional level. Effectively, institutions are pressured by metrics and ranking competition into adopting the recommendations of such tools while individuals are compelled by the institutions where they are employed to adopt such recommendations. With individuals given incentives to publish in high-ranking journals as well as evaluation criteria based on citation performance, the compulsion is clear. In adopting such tools due to the incentives of rankings competition, the university increasingly cedes decision-making power away from themselves and individual researchers into the algorithms used to power Elsevier's tools.

\section{Conclusion}

This paper has presented an overview of the involvement of powerful multinational publishers/data analytics firms in rankings. Clarivate has a dominant position in international rankings in terms of the volume of data supplied even though it has no direct involvement in rankings. In contrast, Elsevier has had a sustained involvement in rankings since 2007 targeting partnerships with dominant rankings such as QS and THE as a way to present its products to 
universities as enabling their rankings performance. Efforts to promote such analytics products complement its existing strategy of vertically integrating scholarly platforms by capturing values of particular key segments of it (Posada \& Chen, 2018, Chen et. al., 2019). Given the increasing pressure faced by universities to perform bibliometrically, universities face pressure to adopt analytics tools promoted by the same data analytics companies which supply rankings.

Rankings are thus a driver for the adoption of particular metrics-emphasizing modalities of research as well as the particular products which facilitate such modalities. Yet the adoption of such modalities represents a ceding of control by universities not only to rankings - which are often the drivers of their decision-making - but also to the algorithms which power the analytics products. As a result, it is argued that the university shifts away from an intrinsic valuation of research and teaching and is increasingly compelled to pay into the rankings-data analytics system. Ultimately, the relationship between data analytics firms and rankings is mutually reinforcing, as well as arguably increasingly harmful to the public missions of the university.

The intent of this paper is to suggest that while there have been studies focused on the impact of rankings on higher education policymaking, relatively little attention has been paid to the increasing influence that digital platforms created by multinational info-utilities and publishers wield in shaping public discourse, knowledge production, and policy formulation across HEl. We need to raise questions about who is in charge of the algorithms and the worldview they encode (Styhre 2018). We also need to ask critical questions about the governance of digital platforms and the compatibility between their private interests and their impact on the public missions of publicly funded institutions. These are all areas that are in urgent need of attention, and we hope this study will stimulate further public debate and critical research in this direction.

\section{Acknowledgement}

We like to thank Mariana Valverde, Angela Okune, Ludo Waltman, Ellen Hazelkorn and an anonymous reviewer for their helpful suggestions on earlier drafts of this paper. Any errors in the paper remain ours.

\section{References}

Adler, N. J., \& Harzing, A. W. (2009). When knowledge wins: transcending the sense and nonsense of academic rankings. Academy of Management Learning \& Education, 8(1), 72-95. 
Aguillo, I. F., Bar-llan, J., Levene, M., \& Ortega, J. L. (2010). Comparing university rankings. Scientometrics, 85(1), 243-256. doi: 10.1007/s11192-010-0190-Z

Alliance News. (2018). PRESS: RELX's Elsevier Plans Bid For Times Higher Education - Sky News. Morningstar. Retrieved June 21, 2020 from

https://www.morningstar.co.uk/uk/news/AN 1543305067255600800/press-relxs-elsevier-plansbid-for-times-higher-education---sky.aspx

Amsler, S. S., \& Bolsmann, C. (2012). University ranking as social exclusion. British Journal of Sociology of Education, 33(2), 283-301. https://doi.org/10.1080/01425692.2011.649835

Andrews, P. C. S. (2018). "Putting It Together, That's What Counts": Data Foam, a Snowball and Researcher Evaluation. In P. V. Moore, M. Upchurch, \& X. Whittaker (Eds.), Humans and Machines at Work: Monitoring, Surveillance and Automation in Contemporary Capitalism (pp. 203-229). Springer International Publishing. https://doi.org/10.1007/978-3-319-58232-0 9

ARWU (2020). Methodology. Retrieved December 29, 2020 from http://www.shanghairanking.com/ARWU-Methodology-2020.html

Ashri, R. (2020). The Al-Powered Workplace: How Artificial Intelligence, Data, and Messaging Platforms Are Defining the Future of Work [Electronic resource]. Springer EBooks.

https://doi.org/10.1007/978-1-4842-5476-9

Aspesi, C., Allen, N. S., Crow, R., Daugherty, S., Joseph, H., McArthur, J. T., \& Shockey, N. (2019, March 29). SPARC Landscape Analysis. , https://doi.org/10.31229/osf.io/58yhb

Aspesi, C., \& Brand, A. (2020). In pursuit of open science, open access is not enough. Science, 368(6491), 574-577. https://doi.org/10.1126/science.aba3763

Beer, D. (2018). Envisioning the power of data analytics. Information, Communication \& Society, 21(3), 465-479. https://doi.org/10.1080/1369118X.2017.1289232

Bougnol, M.-L., \& Dulá, J. H. (2014). Technical pitfalls in university rankings. Higher Education, 69(5), 859-866. doi: 10.1007/s10734-014-9809-y

Budden, R., \& Chassany, A. S. (2013). TPG Capital buys owner of Times Educational Supplement. Financial Times. Retrieved June 21, 2020 from

https://www.ft.com/content/50bb6a1c-e7dd-11e2-9aad-00144feabdc0

Butler, D. (2016). 'Web of Science' to be sold to private-equity firms. Nature News. Retrieved June 21, 2020 from https://www.nature.com/news/web-of-science-to-be-sold-to-private-equityfirms-1.20255.

Chan, L. (2019). Platform Capitalism and the Governance of Knowledge Infrastructure. https://doi.org/10.5281/zenodo.2656601

Chen, G., Posada, A., \& Chan, L. (2019). Vertical Integration in Academic Publishing: Implications for Knowledge Inequality. In Chan, L., \& Mounier, P. (Eds.), Connecting the Knowledge Commons - From Projects to Sustainable Infrastructure: The 22nd International 
Conference on Electronic Publishing - Revised Selected Papers. Marseille: OpenEdition Press. doi:10.4000/books.oep.9068

Clarivate. (2019a). Churchill Capital Corp and Clarivate Analytics Announce Merger Agreement. Retrieved June 21, 2020 from https://clarivate.com/news/churchill-capital-corp-and-clarivateanalytics-announce-merger-agreement/

Clarivate. (2019b). LibGuides: ResBaz: Benchmarking Institutions. Retrieved October 21, 2019 from https://clarivate.libguides.com/resbaz/course8.

Danaher, J., Hogan, M. J., Noone, C., Kennedy, R., Behan, A., De Paor, A., ... Shankar, K. (2017). Algorithmic governance: Developing a research agenda through the power of collective intelligence. Big Data \& Society, 4(2), 2053951717726554.

https://doi.org/10.1177/2053951717726554

Doğan, G., \& Al, U. (2019). Is it possible to rank universities using fewer indicators? A study on five international university rankings. Aslib Journal of Information Management, 71(1), 18-37. doi: 10.1108/ajim-05-2018-0118

Duermeijer, C., Amir, M., \& Schoombee, L. (2018). Africa generates less than $1 \%$ of the world's research; data analytics can change that. Retrieved September 07, 2020 from https://www.elsevier.com/connect/africa-generates-less-than-1-of-the-worlds-research-dataanalytics-can-change-that.

Easterling, K. (2016). Extrastatecraft: The Power of Infrastructure Space (Illustrated edition). Verso.

Elsevier. (2004). Scopus comes of age. Retrieved October 09, 2019 from https://www.elsevier.com/about/press-releases/science-and-technology/scopus-comes-of-age.

Elsevier. (2007). Scopus Custom Data Fuels World Rankings. Retrieved October 09, 2019 from https://www.elsevier.com/about/press-releases/science-and-technology/scopus-custom-datafuels-world-rankings.

Elsevier. (2013). Improving your research management. Retrieved October 09, 2019 from https://www.elsevier.com/research-intelligence/research-initiatives/improving-your-researchmanagement

Elsevier. (2016). Charting an Effective Research Roadmap with Deeper Insights - Royal Melbourne Institute of Technology. Retrieved October 09, 2019 from bit.ly/2KLmz80

Elsevier. (2018). Add power to your decisions. Retrieved October 09, 2019 from https://www.elsevier.com/research-intelligence/resource-library/decision-making-ebooklet

Elsevier. (2019a). Understand Scopus and SciVal's role in university rankings. Retrieved October 09, 2019 from https://www.elsevier.com/research-intelligence/resource-library/scopusscival-university-rankings-ebook 
Elsevier. (2019b). Features - Pure. Retrieved November 30, 2019 from https://www.elsevier.com/solutions/pure/features

Elsevier. (2019c). Elsevier Fingerprint Engine. Retrieved November 30, 2019 from https://www.elsevier.com/solutions/elsevier-fingerprint-engine

Elsevier. (2020a). Case Study: National Cheng Kung University. Retrieved May 20, 2020 from https://www.elsevier.com/ data/assets/pdf file/0016/1001248/ACAD LIB PU SV SC CS N $\underline{\text { CKU Web.pdf }}$

Elsevier. (2020b). Topic Prominence in Science. Retrieved May 20, 2020 from https://www.elsevier.com/solutions/scival/releases/topic-prominence-in-science

Elsevier. (2020c). Better together: Funding Institutional integrates with Pure. Retrieved May 20, 2020 from https://www.elsevier.com/solutions/funding-institutional/releases/better-together

Elsevier. (2020d).Case Study: Arizona State University. Retrieved May 20, 2020 from https://www.elsevier.com/ data/assets/pdf file/0013/1002433/Elsevier SciVal CaseStudy ASU 2020 Screen Final SV WEB.pdf

Eubanks, V. (2018). Automating Inequality: How High-Tech Tools Profile, Police, and Punish the Poor. St. Martin's Press.

Ferguson, A. G. (2017). The Rise of Big Data Policing: Surveillance, Race, and the Future of Law Enforcement. NYU Press.

Fitzpatrick, K. (2019). Generous Thinking: A Radical Approach to Saving the University. Johns Hopkins University Press.

Fyfe, A., Coate, K., Curry, S., Lawson, S., Moxham, N., \& Røstvik, C. M. (2017). Untangling Academic Publishing. A history of the relationship between commercial interests, academic prestige and the circulation of research. https://doi.org/10.5281/zenodo.546100

Garfield, E. (2009). From the science of science to Scientometrics visualizing the history of science with HistCite software. Journal of Informetrics, 3(3), 173-179.

doi:10.1016/j.joi.2009.03.009

Guhr, D. J. (2019). Data, Systems, and the Future of Intelligence-based Hyper Competition between Universities. Session at the QS Edu Data Summit, London.

Hazelkorn, E. (2008). 'Learning to Live with League Tables and Ranking: The Experience of Institutional Leaders', Higher Education Policy, 21/2: 193-215. DOI: 10.1057/hep.2008.1

Hazelkorn, E. (2016). Rankings and the Reshaping of Higher Education: The Battle for WorldClass Excellence (2nd ed. 2015 edition). Place of publication not identified: Palgrave Macmillan. 
HighBeam Research. (1992). Thomson Corporation acquired ISI. (Institute for Scientific Information) (Brief Article). Retrieved June 21, 2020 from

https://web.archive.org/web/20140610220715/http://www.highbeam.com/doc/1G1-

12394745.html

Hinchliffe, L. (2018). Advancing an Integrated Vertical Stack of Publication Services? - The Scholarly Kitchen. The Scholarly Kitchen. Retrieved May 20, 2020 from

https://scholarlykitchen.sspnet.org/2018/08/08/integrated-vertical-stack-of-publication-services/

Inflexion. (2019). Inflexion completes acquisition of Times Higher Education. Retrieved June 21, 2020 from https://www.inflexion.com/news-insights-events/press-releases/2019/inflexioncompletes-acquisition-of-times-higher-education/

Information Today. (2009). Thomson Reuters Launches InCites. Retrieved August 03, 2020 from http://newsbreaks.infotoday.com/Digest/Thomson-Reuters-Launches-EMInCitesEM$\underline{52940 . a s p}$

IREG. (2007). 3rd Meeting of the International Rankings Expert Group. Retrieved October 11, 2019 from http://web.archive.org/web/20090221022309/http://ed.sjtu.edu.cn/IREG-3/IREG3.htm.

Jobbins, D. (2014). New THE split throws rankings world into turmoil. University World News. Retrieved October 11, 2019 from https://www.universityworldnews.com/post.php?story=20141120074833487.

Katzenbach, C., \& Ulbricht, L. (2019). Algorithmic governance. Internet Policy Review, 8(4). https://policyreview.info/concepts/algorithmic-governance

Kellogg, K. C., Valentine, M. A., \& Christin, A. (2019). Algorithms at Work: The New Contested Terrain of Control. Academy of Management Annals, 14(1), 366-410.

https://doi.org/10.5465/annals.2018.0174

de Knecht, S. (2020). Dutch open science deal primarily benefits Elsevier. ScienceGuide. Retrieved August 03, 2020 from https://www.scienceguide.nl/2020/06/open-science-dealbenefits-elsevier/

Labi, A. (2010). 'Times Higher Education' Releases New Rankings, but Will They Appease Skeptics?. The Chronicle of Higher Education. Retrieved October 11, 2019 from https://www.chronicle.com/article/times-higher-education-releases-new-rankings-but-will-theyappease-skeptics/

Lane, P. (1992). Thomson Corporation Acquires Majority Interest in ISI. Questia. Retrieved June 21, 2020 from https://www.questia.com/magazine/1G1-12296761/thomson-corporationacquires-majority-interest-in

Larivière, V., Haustein, S., \& Mongeon, P. (2015). The Oligopoly of Academic Publishers in the Digital Era. Plos One, 10(6). https://doi.org/10.1371/journal.pone.0127502 
Lim, M. A. (2017). The building of weak expertise: the work of global university rankers. Higher Education, 75(3), 415-430. doi: 10.1007/s10734-017-0147-8

Lim, M. A. (2019). Governing Higher Education: The PURE Data System and the Management of the Bibliometric Self. Higher Education Policy. https://doi.org/10.1057/s41307-018-00130-0

Mitsui Group. (2015). Mitsui to participate in British Education Sector Company QS Quacquarelli Symonds Limited. Retrieved June 21, 2020 from

https://www.mitsui.com/jp/en/release/2015/1208366 6474.html

Moed, H., Burger, W., Frankfort, J., \& Raan, A. V. (1985). The use of bibliometric data for the measurement of university research performance. Research Policy, 14(3), 131-149. doi:

10.1016/0048-7333(85)90012-5

Morse, R., \& Vega-Rodriguez, J. (2019). How U.S. News Calculated the Best Global Universities Rankings. Retrieved October 11, 2019 from

https://www.usnews.com/education/best-global-universities/articles/methodology.

MosIUR. (2019). 1200 World's Best Universities: The Three University Missions Ranking 2019 Released. Retrieved October 11, 2019 from https://www.mosiur.org/news/

Mroz, A. (2009). Leader: Only the best for the best. Retrieved October 11, 2019 from https://www.timeshighereducation.com/comment/leader/leader-only-the-best-for-thebest/408968. article?sectioncode=26\&storycode=408968\&c=1.

Nature Index. (2014). Introducing the index. Nature, 515(7526). doi: 10.1038/515s52a

Nelissen, E. (2017). How research analytics is driving success at a Nigerian university. Retrieved September 07, 2020 from https://www.elsevier.com/connect/how-research-analyticsis-driving-success-at-a-nigerian-university

Noble, S. U. (2018). Algorithms of Oppression: How Search Engines Reinforce Racism. NYU Press.

NTU. (2019). Indicators. Retrieved October 11, 2019 from http://nturanking.csti.tw/

Nuzzolese, A. G., Ciancarini, P., Gangemi, A., Peroni, S., Poggi, F., \& Presutti, V. (2019). Do altmetrics work for assessing research quality? Scientometrics, 118(2), 539-562.

https://doi.org/10.1007/s11192-018-2988-z

Onex. (2016). Management's Discussion and Analysis and Financial Statements. Retrieved June 21, 2020 from https://www.onex.com/static-files/2cd59792-63ef-4d2b-8e37-d08c90a8b4c6

O'Neil, C. (2017). Weapons of Math Destruction: How Big Data Increases Inequality and Threatens Democracy (Reprint edition). Broadway Books.

Open Science Monitor. (2019). Updated Methodological Note. Retrieved August 03, 2020 from https://ec.europa.eu/info/sites/info/files/research and innovation/knowledge publications tools and data/documents/open science monitor methodological note april 2019.pdf 
Paasi, A. (2015). Academic Capitalism and the Geopolitics of Knowledge. In The Wiley Blackwell Companion to Political Geography (pp. 507-523). John Wiley \& Sons, Ltd. https://doi.org/10.1002/9781118725771.ch37

Pasquale, F. (2015). The black box society: The secret algorithms that control money and information. Cambridge, MA: Harvard University Press

Petre, C., Duffy, B. E., \& Hund, E. (2019). "Gaming the System": Platform Paternalism and the Politics of Algorithmic Visibility. Social Media + Society, 5(4), 2056305119879995.

https://doi.org/10.1177/2056305119879995

Pooley, J. (2018). Metrics Mania: The Case Against Academia.edu.

https://hcommons.org/deposits/item/hc:17533/

Posada, A. \& Chen, G. (2018). Inequality in Knowledge Production: The Integration of Academic Infrastructure by Big Publishers. ELPUB 2018. https://hal.archives-ouvertes.fr/hal-01816707/

QS. (2020). Methodology. Retrieved August 03, 2020 from https://www.topuniversities.com/qsworld-university-rankings/methodology

Repiso, R., Castillo-Esparcia, A., \& Torres-Salinas, D. (2019). Altmetrics, alternative indicators for Web of Science Communication studies journals. Scientometrics, 119(2), 941-958. https://doi.org/10.1007/s11192-019-03070-7

Reuters. (2018). Top 100 World Innovative Universities - Methodology. Retrieved October 11, 2029 from https://www.reuters.com/innovative-universities-2018/methodology.

de Rijcke, S. (2020). Elsevier and the Dutch Open Science goals. Leiden Madtrics. Retrieved August 03, 2020 from https://leidenmadtrics.nl/articles/s-de-rijcke-cwts-leidenuniv-nl

Robinson-Garcia, N., Torres-Salinas, D., Herrera-Viedma, E., \& Docampo, D. (2019). Mining university rankings: Publication output and citation impact as their basis. Research Evaluation, 28(3), 232-240. https://doi.org/10.1093/reseval/rvz014

RUR. (2019). Round University Ranking Methodology. Retrieved October 11, 2019 from http://roundranking.com/methodology/methodology.html.

Safón, V. (2013). What do global university rankings really measure? The search for the $X$ factor and the X entity. Scientometrics, 97(2), 223-244. doi: S10.1007/s11192-013-0986-8

Schonfeld, R. (2018, January 2). Workflow Lock-in: A Taxonomy. The Scholarly Kitchen. https://scholarlykitchen.sspnet.org/2018/01/02/workflow-lock-taxonomy/

Scimago. (2009). SCImago Institutions Rankings (SIR): 2009 World Report [PDF File]. Retrieved October 11, 2019 from http://web.archive.org/web/20091007135157/http://www.scimagoir.com/pdf/sir 2009 world rep ort.pdf

Shattock, M. (2017). The 'world class' university and international ranking systems: What are the policy implications for governments and institutions? Policy Reviews in Higher Education, 1(1), 4-21. https://doi.org/10.1080/23322969.2016.1236669 
Soh, K. (2014). Multicolinearity and Indicator Redundancy Problem in World University Rankings: An Example Using Times Higher Education World University Ranking 2013-2014 Data. Higher Education Quarterly, 69(2), 158-174. doi: 10.1111/hequ.12058

Sowter, B. (2007). Scopus data ranks the world. Research Trends. Retrieved October 09, 2019 from https://www.researchtrends.com/issue2-november-2007/scopus-data-ranks-the-world/.

Srnicek, N. (2016). Platform Capitalism. Cambridge, UK; Malden, MA: Polity.

Stack, M. (2016). Global University Rankings and the Mediatization of Higher Education. Springer.

Styhre, A. (2018). Governing the university system: How to blend algorithm governance and social meaning. In The Unfinished Business of Governance. Edward Elgar Publishing. https://www.elgaronline.com/view/9781788113137/09 chapter3.xhtml

Taylor, P., \& Braddock, R. (2007). International University Ranking Systems and the Idea of University Excellence. Journal of Higher Education Policy and Management, 29(3), 245-260. doi: 10.1080/13600800701457855

Tennant, J. (2018). Elsevier are corrupting open science in Europe. The Guardian. Retrieved August 03, 2020 from https://www.theguardian.com/science/politicalscience/2018/jun/29/elsevier-are-corrupting-open-science-in-europe

Thelwall, M., Haustein, S., Larivière, V., \& Sugimoto, C. R. (2013). Do Altmetrics Work? Twitter and Ten Other Social Web Services. PLoS ONE, 8(5), e64841.

https://doi.org/10.1371/journal.pone.0064841

TES Global. (2014). TSL Education Renames as TES Global. PRNewswire. Retrieved June 21, 2020 from https://www. prnewswire.com/news-releases/tsl-education-renames-as-tes-global273466301.html

Tes Global. (2018). Tes announces new owners. Retrieved June 21, 2020 from https://www.tes.com/tesglobal/articles/tes-announces-new-owners

THE. (2018). World Academic Summit 2018 Programme. Retrieved October 11, 2019 from http://web.archive.org/web/20190120213916/http://www.theworldsummitseries.com/events/theworld-academic-summit-2018/agenda-959e1e6cf1da41e0a093350cec4d7fdd.aspx.

THE. (2019a). World Academic Summit 2019 Programme. Retrieved October 11, 2019 from http://web.archive.org/web/20190816175024/https://www.timeshighereducation.com/summits/w orldacademic/2019/programme/.

THE. (2019b). THE World University Rankings 2020: methodology. Retrieved October 11, 2019 from https://www.timeshighereducation.com/world-university-rankings/world-university-rankings2020-methodology

van Dijck, J. (2013). The Culture of Connectivity: A critical history of social media. Oxford: Oxford University Press. 
van Dijck, J. (2014). Datafication, dataism and dataveillance: Big Data between scientific paradigm and ideology. Surveillance \& Society, 12(2), 197-208. doi:10.24908/ss.v12i2.4776

van Dijck, J., Poell, T., \& De Waal, M. (2018). The Platform Society: Public Values in a Connective World. Oxford: Oxford University Press.

Yeung, K. (2017). 'Hypernudge': Big Data as a mode of regulation by design. Information, Communication \& Society, 20(1), 118-136. https://doi.org/10.1080/1369118X.2016.1186713

Young, M., Katell, M., \& Krafft, P. M. (2019). Municipal surveillance regulation and algorithmic accountability. Big Data \& Society, 6(2), 2053951719868492.

Wouters, P. (2017). Eugene Garfield (1925-2017). Nature, 543(7646), 492-492.

doi:10.1038/543492a

Vernon, M. M., Balas, E. A., \& Momani, S. (2018). Are university rankings useful to improve research? A systematic review. Plos One, 13(3). doi: 10.1371/journal.pone.0193762

Zitt, M., \& Filliatreau, G. (2007). Big is (made) beautiful: Some comments about the Shanghai ranking of world-class universities. In J. Sadlak \& N.C. Liu (Eds.), The world-class university and ranking: Aiming beyond status (pp. 141-160). Shanghai: UNESCO-CEPES, Institute of Higher Education, Shanghai Jiao Tong University, and Cluj University Press.

Zuboff, S. (2019). The Age of Surveillance Capitalism: The Fight for a Human Future at the New Frontier of Power (1 edition). PublicAffairs. 